\title{
Jornalismo
}

\section{Uma proposta hermenêutica para a Comunicação e a metáfora da Rádio Sucupira}

\section{A hermeneutic proposal for Communications and the metaphor of Radio Sucupira}

\section{Leticia Cantarela Matheus}

Professora Universidade do Estado do Rio de Janeiro (PPGCOM-UERJ). <leticia_matheus@yahoo.com.br>

\section{RESUMO}

Este artigo traz uma reflexão sobre a hermenêutica, suas diferentes abordagens e as perspectivas mais produtivas para as pesquisas em Comunicação, assumindo como ponto de partida o paradigma histórico. O estudo estabelece um diálogo com a historiadora Verena Alberti e enfatiza a contribuição do filósofo francês Paul Ricoeur, na dimensão hermenêutica de sua obra, apontando as aproximações mais profícuas, sobretudo ao seu conceito de metáfora e a sua preocupação com a apropriação. $\mathrm{O}$ artigo aplica algumas dessas reflexões, especialmente acerca da metáfora, a um exercício de análise do programa da CBN chamado "Rádio Sucupira". O boletim jornalístico promove uma paródia da realidade política com a telenovela "O Bem Amado", que foi ao ar pela TV Globo nos anos 1970, acrescentando informação e fazendo emergirem complexos sentidos sobre a atual realidade brasileira.

Palavras-chave: Comunicação. Hermenêutica. Metáfora.

\section{ABSTRACT}

This paper presents a reflection on hermeneutics, their different approaches and the most useful prospects for research in Communication, taking as its starting point the historical paradigm. The study establishes a dialogue with the historian Verena Alberti and emphasizes the contribution of the French philosopher Paul Ricoeur, concerning the hermeneutic dimension of his work, pointing out the most fruitful approaches, especially his concept of metaphor and his concern about appropriation. The article applies some of these reflections, especially about the metaphor, on an exercise of analyzing the CBN program called "Radio Sucupira". The news program promotes a parody of political reality with the soap opera "O Bem-Amado", which aired on TV Globo in the 1970's, adding information and producing complex meanings that emerge about the current Brazilian reality.

Keywords: Communication. Hermeneutics. Metaphor. 
— ste artigo deriva da inquietação sobre as contribuições e os limites da hermenêutica $\amalg$ como método em Comunicação. No fundo do debate, há um problema de ordem epistemológica sobre os processos de comunicação e sobre sua condição como objeto da ciência "do espírito". A interpretação costuma ser bem aceita como condição de significação do discurso. O problema surge quando ela é adotada como método nos trabalhos científicos, recebendo o nome de hermenêutica. A primeira resistência está em reconhecer o produto das ciências sociais como discurso. Além disso, pesa sobre a hermenêutica a crítica sobre sua fragilidade metodológica e seu caráter subjetivo. Tomemos como ponto de partida, e a pretexto comparativo para nossas reflexões, a aplicação que a hermenêutica teve no campo da História, num diálogo inicial com a professora Verena Alberti (1996).

A hermenêutica chega à História para resolver o problema sensível de sua relação epistemológica com as fontes, especialmente aquelas escritas, consagradas como documentos. Para o historiador, a angústia da interpretação correta do texto se justificava pela necessidade de alcançar uma realidade extralinguística que ele revelaria. A interpretação seria, deste modo, uma ferramenta teórico-metodológica para, a partir de marcas simbólicas, chegar aos processos sociais concretos.

O trabalho hermenêutico é o trabalho de compreender algo, de tornar uma realidade estranha conhecida, através do entendimento da coisa. Portanto, diz respeito a uma teoria geral do conhecimento. O grande problema da utilização da hermenêutica na pesquisa em Comunicação é que frequentemente ela é entendida como um recurso metodológico frágil. E esta concepção não está errada, dependendo de como se pensa epistemologicamente a Comunicação. Justificam-se as críticas, na medida em que efetivamente o conceito de interpretação não exclui a inverdade. Uma interpretação pode ser verdadeira ou falsa. O que a tornará verdadeira será seu processo de validação. E esse é outro problema. Dentro de uma lógica simplesmente linguística, a coerência 
interna do enunciado seria suficiente para garantir essa validação, mas, como veremos adiante, existem perspectivas hermenêuticas que assumem que a validação de uma interpretação se dá na confrontação com o mundo social.

O primeiro paradigma hermenêutico, o da exegese, nasce principalmente dos estudos bíblicos, nos quais existe a necessidade da revelação de um sentido oculto, que seria o princípio moral do texto e que poderíamos entender como a verdade de Deus. Portanto, o desvendamento do sentido oculto, o Mistério, é fundamental para os princípios morais das religiões, responsáveis pela institucionalização, logo, pela validação, de certas interpretações bíblicas. O Renascimento teria se caracterizado justamente pela libertação das interpretações dogmáticas tanto da Bíblia quanto de outras obras clássicas.

Esses usos que estamos atribuindo à hermenêutica estariam ainda limitados à ciência da interpretação de texto. Segundo Alberti, tanto o método clássico de interpretação bíblica quanto a filologia, em moda nos séculos XVIII e XIX, eram baseados num tipo de pensamento racional positivista que utilizava as ciências da natureza como parâmetro para o conhecimento social. O mundo tinha sido um organismo. Dali em diante passaria a ser metaforizado num texto disponível à leitura do sujeito que conhece. $\mathrm{O}$ mundo passaria a ser decifrado. Portanto, ainda estamos num tipo de abordagem hermenêutica que não supera a diferença entre objeto e sujeito e que, por isso, mantém-se inadequada como metodologia que propomos.

Até aí, para o historiador, a hermenêutica não teria saído do plano do texto e, portanto, não o permitiria ir para a realidade extralinguistica, o que o obrigava a perceber as fontes de maneira objetiva. Do mesmo modo, para o comunicólogo, não sairíamos do plano da análise de conteúdo. Mas então como usar a hermenêutica para sair do plano do texto e ir para o nível dos processos sociais de significação? Para a produção social de sentido? 
Seria Schleiermacher que passaria do nível da simples interpretação de texto para levá-la a categoria de uma teoria do conhecimento que estuda o próprio processo de compreensão. Segundo Ricoeur (2011, pp. 26-27), foi Schleiermacher o responsável por trazer a hermenêutica para as ciências "históricas" (p. 27), ou seja, sociais, ao pretender transformá-la em método interpretativo. É graças a ele que hoje podemos entender hermenêutica como método. Entretanto, ainda segundo Ricoeur, sua contribuição ainda estaria presa a um caráter romântico porque nasce dele a ideia de que é possível compreender um autor melhor que o próprio, supostamente alcançando seu processo mental em conformidade com seu contexto histórico.

Percebe-se claramente um princípio que reverberou nos estudos literários, com ênfase num caráter subjetivista, como se o gênio do escritor pudesse ser revelado. Essa é a segunda característica deletéria atribuída à hermenêutica mas que posteriormente encontraria alternativas, no plano dos modos de apropriação do texto.

Dilthey traria definitivamente a hermenêutica para as ciências sociais e que nos permitirá considerá-la um paradigma epistemológico possível para a Comunicação. Ele assume que há uma pré-compreensão dos textos na medida em que comparamos uma mensagem com algo que já conhecemos previamente. Há, portanto, um processo de reconhecimento que é já um trabalho de interpretação. Ou seja, "o círculo hermenêutico pressupõe um campo de entendimentos compartilhados, sem o qual não se é capaz de nele ingressar" (Alberti, 1996, p. 39).

Esse processo de conhecimento se apresenta bastante distinto de uma perspectiva subjetivista no sentido de uma psique individual. Entende-se que a própria realidade está contida no texto na medida em que ele é produto da vida social, ainda que não a traduza linearmente, objetivamente. Isso permite ao historiador fazer a crítica da fonte, fazê-la falar para além do seu conteúdo, assim como permite ao comunicólogo compreender os processos e tensões na formação dos discursos e intuir 
sobre os sentidos e apropriações que irá catalisar uma vez posto em circulação na sociedade.

"Com Dilthey, chegamos ao entendimento que a hermenêutica é o fundamento das ciências humanas, porque, diversamente das ciências da natureza, as ciências humanas se consubstanciam com base na compreensão, e não na explicação" (Alberti, 1996, p. 40).

\section{Interpretação na Comunicação}

Optar pela hermenêutica, na Comunicação, é optar pelo reconhecimento da sua natureza em fluxo, por uma perspectiva alternativa a modelos explicativos. Sob a ótica da hermenêutica, os fenômenos comunicacionais devem ser compreendidos, interpretados, em vez de explicados. A hermenêutica seria a trincheira das ciências sociais, pois revelaria a inadequação dos critérios das ciências da natureza. Na nossa opinião, especialmente para a Comunicação, garantiria 1) a presença e a interferência do pesquisador como parte do objeto de pesquisa; 2) o pressuposto que os significados não estão exclusivamente nos textos mas no choque entre o mundo do texto e o mundo social, a partir da interpretação e da apropriação que o público faz desse texto e desse mundo.

Disso decorre que a hermenêutica é não apenas a teoria da interpretação de textos mas a teoria de com a vida se exprime em obras [...]. Por essa razão, a arte da compreensão consiste na interpretação dos resíduos da existência humana conservados pela escrita, e a ciência dessa arte é a hermenêutica."

$$
\text { (Op. cit., p. 42) }
$$


Sem nos aprofundar em toda a trajetória da hermenêutica, é preciso acrescentar outras contribuições, como Wittgenstein, e especialmente Koselleck para a História. A mais importante delas e talvez a mais complexa sobre a qual não vamos nos aprofundar está Heidegger, com sua perspectiva essencialmente filosófica. Segundo Palmer, Heidegger levou a hermenêutica para uma posição radical em relação a Dilthey, entendendo-a para tudo, inclusive para as ciências da natureza. Mas queremos chegar a Gadamer e dele ir a Paul Ricoeur.

Gadamer (1999) serviu para que o historiador avançasse na sua crítica das fontes, ao propor a dialética entre o documento e o pesquisador, anulando a separação entre sujeito e objeto no processo de conhecimento. Segundo esse princípio, a interpretação dos textos resultaria da tensão entre as perguntas que o pesquisador faz ao texto em confronto com as perguntas possíveis de o texto responder. O resultado seria muito mais um processo de autocompreensão histórica do que exclusivamente a compreensão sobre habitantes do passado. Seria essa condição de distanciamento temporal entre sujeito e objeto que produziria o conhecimento em História. Do mesmo modo, podemos pensar que a distância entre as consciências seria a condição mesma da comunicação e que a apreensão de um sentido objetivo é impossível.

Antes de partir para algumas contribuições da hermenêutica de Ricoeur, uma ressalva contra mais uma característica deletéria da hermenêutica que serviu como alerta à História e que também nos serve: o risco do relativismo, como se todas as interpretações fossem possíveis ou igualmente válidas, o que não é verdade. Existem processos de validação das interpretações, mas o mais importante é assumir na Comunicação o fundamento da incompletude do conhecimento. 
As interpretações podem ser indefinidamente refeitas, havendo sempre novos ângulos e pontos de vista, condicionados pelas posições particulares de cada um dos intérpretes. É claro que um bom cientista social deve sempre estar atento ao gap que o separa de seu objeto e incluir a consciência desse gap em sua interpretação - e é isso, afinal, que nos re-ensina essa parte da hermenêutica."

(Alberti, 1996, pp. 20-21)

\section{Referências de mundo}

Para Ricoeur (2000), a defesa da hermenêutica representa uma luta contra o estruturalismo, ainda que ele aceite as análises estruturais como ferramenta para outras etapas interpretativas. Optar pelo método hermenêutico não significa uma redução da concepção comunicacional aos limites do sentido linguístico dos textos, pelo contrário. É ampliar o horizonte de sentido para o mundo.

"A hermenêutica não é outra coisa senão a teoria que regula a transição da estrutura da obra ao mundo da obra. Interpretar uma obra é desvendar o mundo ao qual ela se refere em virtude de sua 'disposição', de seu 'gênero' e de seu 'estilo'”' (p. 337). Portanto, não se trata de abrir mão de uma análise de texto, mas da assunção por parte do comunicólogo (dependendo no método que adota), que importa a relação do texto com o mundo exterior. Não se trata, pois, de procurar a intenção do autor. Não é esse tipo de movimento subjetivo, psicologizante, de ir ao encontro da experiência do outro, que está em jogo, mas o direito de passar da estrutura da obra ao mundo por ela projetado. Do mesmo modo, não nos interessa tanto ir em busca de intenção maquiavélica, ideologizada, das empresas de comunicação, mas da ação sobre o mundo através das relações de comunicação. 
Ricoeur nos permite embaralhar as fronteiras entre ficção e realidade. Para ele, a literatura teria sido lida de modo empobrecido pela semiótica na medida em que procura o sentido interno da obra, onde só há conotação. Sua função referencial seria suspensa. Durante séculos, o historiador não pôde ver na literatura fonte historiográfica, pois supostamente ali não havia denotação. A arte estaria condenada ao prazer estético, aos sentidos, sem nenhuma pertinência às coisas do mundo referencial. De modo análogo, porém inverso, o discurso da ciência seria pura denotação. O comunicólogo igualmente não costuma se permitir ver relação entre ficção/entretenimento e jornalismo/documentário, para onde só deveria haver denotação. No estudo apresentado a seguir, sobre a "Rádio Sucupira", veremos uma experiência na qual o mundo da obra ficcional é capaz de falar tanto ou mais da realidade contemporânea do que matérias jornalísticas ou artigos e editoriais.

A grande contribuição de Ricoeur para a incorporação de sua hermenêutica nos estudos em Comunicação é a proposta de integração da perspectiva linguística (discurso, enunciação, narração) com a perspectiva significativa. Portanto, é preciso compreender esses dois planos do discurso, a partir da dialética entre o linguístico e o extralinguístico. Porém, para Ricoeur, o extralinguístico não se encontra apenas na produção discursiva (enunciação). É preciso ir para o momento em que o texto volta ao mundo. É preciso chegar à interpretação e à seguinte apropriação.

A chave para a comunicação, em Ricoeur, é o modelo do diálogo. O código deve estar sempre subordinado à sua função de operar uma conexão. A comunicação é um enigma e mesmo um milagre, porque o estar junto, enquanto condição existencial da possibilidade de qualquer estrutura dialógica do discurso, surge como um modo de ultrapassar ou de superar a solidão fundamental de cada ser humano, uma distância comunicacional que, paradoxalmente, é sua condição de existência. 
Por solidão não quero indicar o fato de, muitas vezes, nos sentirmos isolados como numa multidão, ou de vivermos e morrermos sós, mas, num sentido mais radical, de que o que é experimentado por uma pessoa não se pode transferir totalmente como tal e tal experiência para mais ninguém. A minha experiência não pode se tornar diretamente a sua. Um acontecimento que pertence a um fluxo de consciência não pode transferir-se como tal para outro. E, no entanto, algo se passa de mim para você, algo se transfere de uma esfera de vida para outra. Este algo não é a experiência enquanto experimentada, mas a sua significação. Eis o milagre. A experiência experimentada, como vivida, permanece privada, mas o seu sentido, a sua significação torna-se pública. A comunicação é, deste modo, a superação da radical não comunicabilidade da experiência vivida enquanto vivida."

(Ricoeur, 2000, pp. 27-28).

Da dialética do acontecimento à significação do enunciado acontece uma terceira coisa, que é a comunicação, isto é, a transcendência. Comunicar-se é se exteriorizar em direção ao outro, é abrir o horizonte de si e do outro e será o contexto, a situação comunicacional, o que irá filtrar a polissemia das ambivalências do discurso e o que, no nosso caso, irá regular a validação de certas interpretações em detrimento de outras.

Portanto, Ricoeur nos ajuda a escapar ao estruturalismo, a fugir do sentido como ordem interna da estrutura e voltar-se à referência, que é a ligação do texto com o mundo. Mesmo que a função referencial seja primordial em alguns tipos de discurso, como o jornalístico que estamos tratando, essa referência está, para Ricoeur, em outro lugar que não na “origem” do discurso. É essa inversão seu grande mérito e que 
nos ajuda a pensar nos usos e nas apropriações discursivas, não exclusivamente nas suas condições de produção. A referência, para Ricoeur, está no mundo que o texto projeta, não naquele que ele supostamente representa. E a ligação que construíamos entre o discurso e o mundo projetado é que será a interpretação. A referência só existe no uso. Referir é aplicar as palavras à realidade, não extraí-la de uma realidade primeira, original, representada fielmente ou não. Com isso, esperamos poder reduzir o sofrimento de quem se angustia tentando manter as fronteiras entre realidade e ficção.

Segundo Ricoeur (2000, p. 48), a ficção não corresponde à abolição da referência. O discurso não deixa de ser sobre alguma coisa. Os textos poéticos ainda falam do mundo. O que ocorre é que "o apagamento da referência ostensiva e descritiva liberta um poder de referência para aspectos do nosso ser-no-mundo que não se podem dizer de um modo descritivo direto, mas só por alusão, graças aos valores referenciais das expressões metafóricas e, em geral, simbólicas". Assim, recursos ficcionais, como a metáfora, podem ampliar a perspectiva sobre o mundo, às vezes muito mais, onde os textos de referência ostensiva não funcionam tão bem, e, paradoxalmente, libertam uma potência referencial.

Para mim, o mundo é o conjunto das referências desvendadas por todo o tipo de texto, descritivo ou poético, que li, compreendi e amei. E compreender um tex to é interpolar, entre os predicados da nossa situação, todas as significações que constituem um mundo a partir de nosso ambiente social. É este alargamento do nosso horizonte de existência que nos permite falar das referências descortinadas pelo texto ou do mundo aberto pelas exigências referenciais da maior parte dos textos."

(Ricoeur, 2000, p. 49). 
A metáfora é uma estrutura de duplo sentido cuja primeira interpretação esclarece a segunda. Existe um sentido literal e outro figurado (ou um explícito e outro implícito), um denotado outro conotado. A significação global da metáfora dependerá da relação entre as duas significações. Ricoeur explica que a metáfora é um tipo de designação que usa o nome de uma coisa para outra, cuja interpretação (decodificação) dependerá de um método comparativo. Na prática, são dois territórios linguísticos que ampliam o sentido do discurso, não por uma mera substituição de termos por semelhança, mas por uma substituição criativa, segundo a qual a tensão entre esses dois campos semânticos faz emergir outros sentidos (Ricoeur, 2000, p. 61).

Mas é preciso deixar claro que essa tensão não é entre dois termos de uma enunciação mas entre duas interpretações opostas, o que gera uma "absurdidade". Assim, a metáfora não existe em si mesma mas somente numa e por uma operação heurística. Graças a essa operação metafórica, é possível produzir sentido onde uma leitura literal seria absurda. O que seria uma impertinência semântica, se o texto fosse lido ao pé da letra, resulta numa torção metafórica entre interpretações com um longínquo parentesco improvável. Segundo Ricoeur, esse tipo de inovação semântica de onde emergem novos significados não se encontra em dicionários, como sinônimos. São metáforas vivas operadas somente no uso da linguagem (p. 63). O conceito dele de metáfora é, portanto, puro uso, só existe no uso e só faz sentido na ação de usar, escapando à análise estruturalista, de conteúdo. Como acontecimento do discurso, revela correlações inauditas sobre a realidade.

As metáforas genuinas não se podem traduzir. Só as metáforas de substituição são susceptíveis de uma tradução, que poderia restaurar o sentido literal. As metáforas de tensão não são traduzíveis, porque criam 
o seu sentido. Isto não é dizer que não se possam parafrasear, mas apenas que uma tal paráfrase é infinita, incapaz de exaurir o sentido inovador. A metáfora não é um ornamento do discurso. Tem mais do que um valor emotivo, porque oferece uma nova informação. Em suma, uma metáfora diz-nos algo de novo acerca da realidade."

(Ricoeur, 2000, p. 64)

Ricoeur radicaliza e aplica a teoria metafórica ao conhecimento científico, assumindo que ela possui sim função referencial, não apenas ornamental. Além do sentido enquanto pura função predicativa, ela possui referência enquanto pretensão a dizer algo acerca da realidade, em suma, o seu valor de verdade. É verdade que todo discurso possui uma organização interna para que seja entendido mas também tem a pretensão de dizer alguma coisa acerca de alguma coisa. O que é esse valor referencial? Parte da sua função heurística, a descoberta seja de uma metáfora ou de um modelo científico. Por isso, Ricoeur afirma que um modelo teórico é essencialmente um procedimento heurístico que serve para demolir uma interpretação inadequada e abrir o caminho a uma interpretação nova, mais ou menos adequada, revelando e produzindo novas conexões intelectuais (Ricoeur, 2000, pp. 78-79).

\section{A absurdidade da Rádio Sucupira}

A "Rádio Sucupira” é um boletim semanal, com duração de 3 minutos, que vai ao ar nas noites de sexta-feira na Rádio CBN em rede nacional, em torno das $21 \mathrm{~h} 30^{1}$. Desde 2005, quando criado, já foram veiculadas mais de 400 edições, no encerramento do Jornal da CBN Primeira Edição. Inicialmente, chamava-se Bandinha, em referência ao LP da trilha sonora da novela, "Bandinha de Sucupira". Trata-se de um comentário sobre as principais notícias da semana. O diferencial é que o comentarista é o personagem 
Odorico Paraguaçu. A edição é montada exclusivamente com trechos da telenovela da TV Globo, "O Bem-Amado", mesclados com as sonoras mais significativas do noticiário político da semana, formando uma síntese entre realidade e ficção. A "Rádio Sucupira" é, mais do que uma paródia, metáfora da própria CBN. Ao lembrar a Rádio Difusora Sucupira, "aquela que não erra na mira", como dizia o slogan, a CBN traz para seu universo semântico o referencial da telenovela, promovendo a torção de sentidos, entre o conotado e o denotado.

Assim como na trama original, Sucupira se confunde com o Brasil. Mas o que levaria uma emissora de rádio que segue o modelo all news, com alto padrão de qualidade, incluir em sua programação um conteúdo ficcional? A resposta pode estar na informação que a narrativa ficcional carrega e, por que não, na carga emocional e sensacional que as narrativas jornalísticas podem fornecer para melhor compreender a realidade.

"O Bem-Amado" foi ao ar de janeiro a outubro de 1973, no horário das 22h (Dicionário da TV Globo, 2003, pp. 39-40). Em plena ditadura militar, a trama escrita por Dias Gomes chegou a sofrer censura. No meio da novela, o coronel Odorico Paraguaçu, interpretado por Paulo Gracindo, teve que passar a ser chamado de prefeito, nominação que, evidentemente, não traduzia a dimensão do ele representava, como arquétipo do coronelismo no Brasil. Seu capanga, Zeca Diabo, papel de Lima Duarte, também teve que deixar de ser referido como capitão. $O$ enredo central girava em torno da vida política de Sucupira, onde Odorico se elegera prometendo construir um cemitério na cidade. O problema é que ele não conseguia inaugurá-lo, pois ninguém morria. Para resolver o problema, Odorico contrata o matador Zeca Diabo. A ironia está em que é ele próprio que é morto, conseguindo finalmente "usar" o cemitério como o primeiro "cliente". O plano de Odorico era ascender na política, chegando ao governo ou até mesmo, seu sonho, presidência. 
Essa trama central é atravessada por falcatruas e mazelas do universo político brasileiro. Odorico é um personagem riquíssimo em bordões, como "Para frente, Sucupira!", escolhido para abrir o boletim noticioso. O material audiovisual do drama é repleto de bordões e diálogos marcantes de Odorico com outros personagens, principalmente com Dirceu Borboleta (Emiliano Queiroz). São esses diálogos e bordões que entram no programa da CBN como comentários para os acontecimentos da semana. A trilha sonora original da telenovela também tem papel fundamental no apagamento das fronteiras entre realidade e ficção. Inclusive o "carimbo", 'Pra frente, Sucupira!', foi extraído do LP. Mais recentemente, a Globo Marcas lançou o DVD da novela, material que também passou a ser usado. Inicialmente, a CBN extraía o áudio diretamente do material de arquivo da novela, emprestado pelo Centro de Documentação da TV Globo.

A associação entre realismo e ficção no jornalismo é antiga. Desde os folhetins, inspirados no noticiário, até o jornalismo literário, passando chamado pelo jornalismo Gonzo, as fronteiras entre a denotação e a conotação são transpassadas nas narrativas jornalísticas diariamente. Este é apenas mais um exemplo que evidencia não apenas a impertinência da tese da fronteira para a compreensão dos processos de significação da realidade, como chama a atenção para a proficuidade das misturas.

Para criar Odorico, Dias Gomes já tinha se baseado num personagem real do Espírito Santo, que contava como plataforma política a criação do cemitério municipal. Durante a exibição da novela, também houve referências ao então recente caso Watergate. Em entrevista à autora, o editor do programa, Edmilson Fernandes, contou que a ideia original surgiu entre a equipe do Jornal da CBN na época da eleição do deputado Severino Cavalcanti à presidência da Câmara federal: 
Aqueles discursos caricatos lembravam muito os do prefeito Odorico Paraguaçu. Começamos, então, a mesclar declarações dos políticos atuais com as do prefeito de Sucupira durante o Jornal da CBN. Com o tempo, começamos a juntar várias sonoras e formamos um quadro fixo."

(Fernandes, 03/05/2013)

A edição leva em média duas horas. $O$ trabalho consiste na seleção das principais sonoras da semana e na pesquisa sobre o que Odorico falou sobre aquele tema. $\mathrm{O}$ mais incrível é que existem frases do personagem que se adequam a quase todos os temas da atualidade, algumas se encaixando perfeitamente.

A equipe do Jornal da CBN, principalmente o Paschoal Jr., da mesa de som, colabora, dando ideias. Aliás, foram o Paschoal e o Heródoto Barbeiro que começaram essa história, usando frases do disco "Bandinha de Sucupira", que traz a trilha do seriado o Bem-Amado. Depois que tornamos o quadro fixo, o parceiro principal é o sonoplasta Claudio Antonio (o Claudinho). Desde o início, ele mixa as falas e me ajuda a formar a "historinha" com o material de 'O Bem-Amado'."

(Fernandes, 03/05/2013)

A vinheta de abertura é feita com a música "O Bem-Amado", de Toquinho e Vinícius de Moraes. Por mais inverossímil que pareça, Odorico possui frases que ilustram, comentam e explicam quase todas as declarações atrapalhadas das 
autoridades brasileiras. Segundo Fernandes, "como os escândalos na política brasileira só mudam de nome e de partido, o discurso do prefeito Odorico Paraguaçu continua atual". O resultado é surpreendente. Como diz Ricoeur, uma terceira interpretação é produzida a partir dessa metáfora entre o passado recente e presente tão arcaico do Brasil. A impertinência entre ficção e jornalismo talvez não seja tão acentuada quanto a impertinência dos tempos. Ao escutar a "Rádio Sucupira" na CBN, o ouvinte já não sabe se a quem pertence cada fala e se está num presente irreal ou num passado da tradição política brasileira que nunca se foi.

A produção parte do pressuposto que o público ouvinte conhece os assuntos tratados. A maior parte dos ouvintes inclusive ouviu as tais declarações polêmicas ou cínicas ou infelizes durante a semana, então, quando ouve as sonoras de Odorico, já as associa imediatamente à notícia original e estabelece uma nova leitura do acontecimento e do próprio contexto noticioso. De certa forma, Odorico ajuda o ouvinte a interpretar sua realidade, a alcançar um sentido para os acontecimentos que o noticiário tradicional talvez não revelasse em toda a sua riqueza. "Suas frases escancaram determinadas declarações de políticos que ficam nas entrelinhas" (Fernandes, 2013). Essa releitura se perpetua em novas atualizações de sentido, como, por exemplo, em vídeos no YouTube, produzidos e postados pelos ouvintes-fãs da "Rádio Sucupira". Os ouvintes "ficam indignados com os Odoricos de hoje, mas se divertem com o deboche. Alguns deles montam vídeos no Youtube com o quadro e ajudam a divulgar o nosso trabalho", contou Edmilson.

Vejamos a seguir três boletins que foram ao ar nos dias 29 de março, 12 de abril, e 31 de maio. Pegamos um por mês, numa sequencia de três meses, com temas centrais aleatórios. O primeiro falava da indicação do deputado do PSC, Marco Feliciano, para presidente da Comissão de Direitos Humanos. O segundo tratava da insistência da presidente Dilma Rousseff em negar o aumento crescente da inflação. E o terceiro, 
dos gastos excessivos na construção de estádios para a Copa do Mundo de Futebol. A teoria da metáfora de Ricoeur ajuda nessas análises, embora também pudéssemos ter optado por outras soluções teórico-metodológicas.

Começa o programa com a sonora da "Rádio Difusora de Sucupira": "Nós somos da TV Aratu", e a repórter pergunta se a proibição do beijo não seria uma forma de violência. Em seguida, entra a sonora real com a resposta do deputado Feliciano:

- Não sou homofóbico, não sou contra o homossexual. Sou contra suas práticas, sou contra suas promiscuidades. Eu não quero que as minhas filhas saiam à rua e vejam dois homens barbados, com a perna "rapada" beijando a boca um do outro. Querem beijar, beijem dentro das suas casas, quem fazer suas porcarias, façam dentro dos seus quartos."

Em seguida, entra o "carimbo": "Pra frente, Sucupira!" Somente esta primeira intervenção de Odorico já possui muito significado. Percebe-se o atraso, o retrocesso no processo histórico revelado pela tensão com a frase bem aplicada, como se o comentário do prefeito de Sucupira já fosse suficiente para dizer coisas não seriam autorizadas ao jornalista dizer.

A partir do 0:48", volta a sonora de Feliciano pedindo que o grupo de manifestantes fosse retirado do plenário e depois pede calma. Em seguida, há a emenda por sobreposição das sonoras com dele dizendo "Calma! Jesus é bom! Fiquem tranquilos" com o trecho de Odorico falando a mesma coisa: “Calma, minha gente! Calma!". A interpolação entre as falas de Feliciano e de Odorico, sobretudo pela fusão das sonoras, causa uma indissociação entre os personagens e se estabelece assim a coincidência 
narrativa entre os dois personagens. A partir daí, qualquer fala de Odorico passa a ser compreendida pela ouvinte como sendo de Feliciano. Como diria Ricoeur, instaurase o reino do "como se", isto é, o mundo do texto, segundo o qual é utilizado como a referência situacional, reproduzindo uma condição dialógica análoga à realidade.

Após voltar ao ambiente real da Câmera federal, há nova mescla com o som ambiente de um comício em Sucupira: “Ome, ome ome Odorico não é homem!” e entra o seguinte diálogo de Odorico com sua secretária:

Odorico - O que é que eles estão dizendo? Que eu não sou homem? Secretária - Não. Não liga para isso não. Finja que não está ouvindo. Odorico - Como é que eu posso fingir que não estou ouvindo se a cidade toda está escutando?

Secretária - É a democracia. Eles têm o direito de dizer o que quiser... Odorico - Democracia comigo é no cacete! Eu admito tudo menos que duvide da minha masculinidade."

O trecho diz mais do que os jornalistas poderiam dizer num noticiário comum, pois, desde o primeiro momento em que o deputado fora escolhido para a comissão, passou a ser atacado nas redes sociais como homossexual "enrustido". Faziam deboches dele, comparando-o a um transexual chamado Vanessão, cuja fotografia circulava na rede, sugerindo que fosse o próprio antes da chamada "cura gay". Tal referência seria impensável num programa jornalístico, mas bastaria o povo de Sucupira gritar "Ome, ome, ome, Odorico não é homem" para que fosse lembrada. Portanto, o referencial não é a notícia representada, no sentido de reprodução, mas o conjunto possível de interpretações projetadas no mundo. 
Repórter ficcional - Coronel, o que o senhor acha do homossexualismo? Odorico - Em Sucupira não tem disso não... Lá mulher é mulher e homem é homem.

Então Feliciano responde:

- Eu represento um segmento. 211 mil pessoas votaram em mim com esse pensamento. Nós temos essa cultura. Não critico quem faz. Faça, mas faça de uma maneira que não choque os demais.

Volta para Odorico:

- O povo não está comigo? O povo não me elegeu? Eu ainda tenho companheiros leais, capazes de morrer por minha causa."

A edição termina com Odorico berrando, como se estivesse num palanque:

- Vou acabar com essa iniquidade e, porque não dizer, essa vergonhosidade!"

(Rádio Sucupira, CBN, 29/03/2013)

Na sexta-feira, dia 12 de abril, foi ao ar a edição "Inflação está morta", na qual o alvo era a presidente Dilma. O Índice de Preços ao Consumidor Amplo (IPCA) havia subido $0,47 \%$ em março e superado o teto esperado para o acumulado de 12 meses. Então o programa começa com Odorico recebendo uma comissão de parlamentares:

Odorico - A que devo a honra de receber tão dignises e simpáticos representantes da tradicional família sucupirana? 
Parlamentar - Nós estamos aqui representando a CCC.

Odorico - CCC? - pergunta Odorico.

Parlamentar - Comissão de Combate à Carestia.

Odorico - Ah.

Parlamentar - E viemos pedir ao Sr prefeito que tome providências enérgicas contra a alta desenfreada do custo de vida. Porque do jeito que as coisas vão muito em breve os pobres não terão o que comer. E vão morrer de fome. O senhor prefeito evidentemente não vai negar a inflação, vai?

Odorico - A inflação está morta!

Parlamentar - Mas morta como, se já passou de 100\%?

Odorico - Isso foi pra trazmente, para frentemente é o que importa.

Nesse momento, o ouvinte imediatamente lembra de Dilma negando a inflação. Existe o fato denotado, que é o anúncio do índice do IPCA, mas existe também a interpretação acerca da teimosia de Dilma. No caso de Sucupira, a inflação já tinha passado de $100 \%$ e o prefeito continuava negando. Dilma iria pelo mesmo caminho? Até quando? Além disso, as expressões de Odorico, para falar e não dizer nada, e seu cinismo remetiam a tantos episódios que lembramos em nossa memória que iluminam muito da tradição política brasileira. Entra em seguida uma entrevista com o ministro da Fazenda, Guido Mantega, feita naquela semana:

- O governo não vai poupar esforços para conter a inflação e impedir que ela se propague.

Novamente a vinheta: "Para frente, Sucupira!" 
A vinheta entra em lugares improváveis das narrativas e o ouvinte leva um susto, como se a ficção o fizesse acordar de um transe para a realidade. O slogan é obviamente uma alusão ao bordão político da década de 1970, "Para frente, Brasil”. Ou seja, quanto maior conhecimento geral, de cultura midiática e de cultura política, do público, mais amplo será o efeito metafórico da torção metafórica Sucupira-Brasil, pois mais ambiguidades e contradições em profundidade histórica vão sendo reveladas por uma operação ficcional.

Repórter ficcional - Coronel, eu queria saber, é verdade que o senhor vai a Brasília propor um plano de aumento da inflação? - pergunta o repórter feito pelo ator Carlos Eduardo Dolabella. Odorico responde:

Odorico - Não somentemente o aumento da inflação como a manutenção da inflação até o ano 2000.

Dilma - Eu não concordo com políticas de combate à inflação que olhem para a questão da redução do crescimento econômico. Esse receituário que quer matar o doente em vez de curar a doença ele é complicado, você entende? Eu vou acabar com o crescimento no país?

Odorico - Nada de combater a inflação. Eu quero a inflação a 200\%, 300\%!"

(Rádio Sucupira, CBN, 12/04/2013)

O terceiro programa evidencia o provincianismo brasileiro e o poder do discurso vazio, quando a realidade é mais inverossímil que a ficção. Ele foi ao ar no dia 31 de maio, tendo como tema a inauguração dos primeiros estádios para a Copa das Confederações, que houve em junho, e para o Mundial, em 2014. Começa a secretária de Odorico: 
Secretária - Alguns vereadores estão apoiando a proposta. Eles estão querendo fazer o "Sucupirão".

Odorico - Por que eles não vão fazer estádio no raio que o parta?

Corte seco para a sonora da Dilma:

- Um ano atrás diziam que nós não iríamos construir os estádios. Pois o que estamos vendo são estádios construídos e sendo entregues.

- Pra frente, Sucupira!

Volta para Dilma:

- É muito orgulho para nós sermos capazes de demostrar ao mundo que temos um estádio dessas proporções, com essa qualidade.

Odorico - Eu tenho certeza que vai ser aprovada por todos os países do primeiro mundo, como talqualmente do segundo e acredito que até do terceiro mundo também.

Dilma - Não é qualquer país que tem essa qualidade e essa beleza nos seus estádios.

Odorico - É com a alma enxaguada na alegria e no orgulho que o povo sucupirano hoje se engalana a receber nesse gramado esverdescente o talentoso e valentoso time dos artistas."

Depois da frase "O Brasil vai dar uma grande lição ao mundo", do ex-jogador de futebol Ronaldo Nazário de Lima, volta para Odorico:

- E aproveito a oportunidade para dizer dos principalmentes da minha plataforma. Ponto um é fazer Sucupira atuar no campeonato nacional. Dilma - Nós somos capazes de mostrar que o Brasil dará uma imensa qualidade à Copa das Confederações. 
Ministro - O teste no Mané Garrincha ocorreu agora com o clássico de Santos e Flamengo onde nós vimos que não houve nenhum incidente.

Torcedor - Comprei uma cadeira que não existe; F33 F34 e só vai até F33. Tem um monte de gente como esse mesmo problema e ninguém consegue dar uma solução. Ninguém! Ninguém!

Odorico - Além desse considerando, eu devo aduzir que como estadista eu coloco o esporte entre os primeiramente da minha administração.

Dilma - Nós somos capazes sim não só de ganhar o jogo dentro do campo como de ganhar o jogo fora do campo.

Odorico - Não esqueçam que o lema é dólar para frente, Odorico presidente!"

(Rádio Sucupira, CBN, 31/05/2013)

\section{Considerações finais}

Embora superficiais, essas análises servem para mostrar que é possível utilizar a hermenêutica como método em Comunicação. A análise poderia ter sido feita por outras opções teóricas. O importante é mostrar que um método não é uma fórmula prévia, mas uma solução criada pelo pesquisador em função das teorias adotadas para elaborar problemas e fazer perguntas.

Concluímos que a abordagem linguística é apenas uma das noções possíveis de interpretação dos discursos e que revelar a estrutura do texto é explicá-lo mas não necessariamente compreendê-lo. Do nosso ponto de vista, é preciso reenviar o discurso ao mundo social, obtendo interpretações válidas com o confronto com nosso próprio conhecimento prévio e com aquilo que projetamos a partir dele.

Apenas para encerrar com alguns procedimentos metodológicos sugeridos por Ricoeur e que deixamos para desenvolver com mais espaço em outra oportunidade: identificar as unidades de ação, procurar as relações entre os núcleos de ação, 
identificar as temporalidades narrativas e o modo de encadeamento temporal das ações dramáticas, procurar os atores nas narrativas e seus papeis (quem fez o que a quem), procurar os principais eixos semânticos e estabelecer a hierarquia das ações. Por fim, perceber como o narrador e o leitor se encontram no texto. Esse tipo de análise é útil como um estágio, mas é preciso passar para um segundo nível crítico, o que seria uma interpretação em profundidade, um estádio diferente do arco hermenêutico que vá além da explicação. Que seja também compreensão. Compreender não é chegar à situação original do discurso mas procurar qual o mundo possível para o qual ele aponta. "O sentido do texto está à sua frente" (Ricoeur, 2000, p. 99).

\section{REFERÊNCIAS}

ALBERTI, Verena. A existência na história: revelações e riscos da hermenêutica. Estudos históricos Historiografia, Rio de Janeiro, v. 9, n. 17, pp. 31-57, 1996. Disponível em: <http://bibliotecadigital.fgv.br/dspace/ bitstream/handle/10438/4153/413.pdf?sequence=1>. Acesso em: 24 jul. 2013.

BEM AMADO (O). Verbete. Dicionário da TV Globo. Vol. 1. Rio de Janeiro: Zahar, 2003. pp. 39-40.

FERNANDES, Edmilson. Entrevista à autora em 03/05/2013, por e-mail.

GADAMER, Hans-Georg. Verdade e método - Traços fundamentais de uma hermenêutica filosófica. Petrópolis (RJ): Vozes, 1999.

RICOEUR, Paul. Hermenêutica e ideologias. Petrópolis (RJ): Vozes, 2011.

. Teoria da interpretação. Lisboa: Edições 70, 2000.

\section{Material empírico:}

Não duvide de minha masculinidade. <http://cbn.globoradio.globo.com/colunas/radio-sucupira/2013/03/29/ NAO-DUVIDE-DE-MINHA-MASCULINIDADE.htm\#ixzz2VUIsKz1H>.

A inflação está morta. <http://cbn.globoradio.globo.com/colunas/radio-sucupira/2013/04/12/INFLACAOESTA-MORTA.htm\#ixzz2VUIgUrC6>.

Como estadista, coloco o esporte entre os primeiramente da minha administração. <http://cbn.globoradio. globo.com/colunas/radio-sucupira/2013/05/31/COMO-ESTADISTA-COLOCO-O-ESPORTE-ENTRE-OSPRIMEIRAMENTE-DA-MINHA-ADMINISTRACAO.htm>. 


\section{NOTA}

1 Central Brasileira de Notícias (CBN) foi criada em 1991 e pertence às Organizações Globo. Possui quatro emissoras próprias e 28 afiliadas no Brasil.

Recebido em: 24 jul. 2013

Aceito em: 07 mar. 2014

\section{Endereço do autor:}

Leticia Cantarela Matheus <Letícia_mateus@yahoo.com.br>

Faculdade de Comunicação Social - UERJ

Rua São Francisoo Xavier, 524, $10^{\circ}$ andar

Pavilhão João Lyra Filho - Maracanã

20550-900 Rio de Janeiro, RJ, Brasil 